\title{
Considerations in designing systems for large scale production of human cardiomyocytes from pluripotent stem cells
}

\author{
Allen Chen, Sherwin Ting, Jasmin Seow, Shaul Reuveny and Steve Oh*
}

\begin{abstract}
Human pluripotent stem cell (hPSC)-derived cardiomyocytes have attracted attention as an unlimited source of cells for cardiac therapies. One of the factors to surmount to achieve this is the production of hPSC-derived cardiomyocytes at a commercial or clinical scale with economically and technically feasible platforms. Given the limited proliferation capacity of differentiated cardiomyocytes and the difficulties in isolating and culturing committed cardiac progenitors, the strategy for cardiomyocyte production would be biphasic, involving hPSC expansion to generate adequate cell numbers followed by differentiation to cardiomyocytes for specific applications. This review summarizes and discusses up-to-date two-dimensional cell culture, cell-aggregate and microcarrier-based platforms for hPSC expansion. Microcarrier-based platforms are shown to be the most suitable for up-scaled production of hPSCs. Subsequently, different platforms for directing hPSC differentiation to cardiomyocytes are discussed. Monolayer differentiation can be straightforward and highly efficient and embryoid body-based approaches are also yielding reasonable cardiomyocyte efficiencies, whereas microcarrier-based approaches are in their infancy but can also generate high cardiomyocyte yields. The optimal target is to establish an integrated scalable process that combines hPSC expansion and cardiomyocyte differentiation into a one unit operation. This review discuss key issues such as platform selection, bioprocess parameters, medium development, downstream processing and parameters that meet current good manufacturing practice standards.
\end{abstract}

\section{Introduction}

Cardiovascular disease is the leading cause of death globally, accounting for 244.8 per 100,000 deaths in 2008 [1]. Although novel drugs and devices have enhanced the quality of life for patients with cardiovascular disease, they have not necessarily decreased morbidity or mortality [2]. Human adult cardiomyocytes have a turnover rate of less than $1 \%$ per year [3], indicating a limited regenerative capacity of the human adult heart. Resident cardiac stem cells and cardiac progenitor cells have been reported in the heart $[4,5]$ and they have the ability to differentiate into all the constituent cell lineages of the myocardium, therefore participating in the repair process of a myocardial injury [6]. However, these cells cannot restore very large infarcts and an external therapeutic intervention is needed to compensate the heart's inadequate intrinsic repair ability. As such, heart transplantation currently remains the only definitive treatment for end-stage patients. Unfortunately, donor hearts are critically deficient; thus, new therapeutic paradigms for heart failure are warranted.

A potential cure for heart failure can be achieved through cardiovascular cell therapy, which aims to repopulate damaged myocardium with new contractile cells and restore the heart. Pluripotent stem cells have nearly unlimited self-renewal capability in vitro and have the ability to differentiate into all three germ layers, thus giving rise to all cell types of the human body [7]. Since the initial demonstration that contracting cardiomyocytes can be generated from both human embryonic stem cells (hESCs) [8] and human induced pluripotent stem cells (hiPSCs) [9], stem cell technology has raised hopes for a source of unlimited numbers of human cardiomyocytes to rebuild the heart. In experimental animal models of acute myocardial infarction, transplantation of hESC-derived cardiomyocytes to the injury site has been shown to benefit heart function [10-12]. It was shown that the functional improvement of the heart is transient and presumably due to paracrine contributions of transplanted hESC-derived cardiomyocytes

\footnotetext{
* Correspondence: steve_oh@bti.a-star.edu.sg

Bioprocessing Technology Institute, 20 Biopolis Way, Centros \#06-01,
} Singapore 138668, Singapore 
that led to increased vascularization [13]. Nevertheless, results presented so far are heartening because they present a prospect for survival and maturation of cardiomyocytes [14]. In cases of myocardial infarction, one billion cells potentially need to be replaced [15], emphasizing the need for reproducible and high yield differentiation protocols.

Besides their significance in regenerative medicine, cardiomyocytes generated in vitro are also needed for cardiac safety pharmacology testing. Unforeseen cardiotoxicity is one of the most common causes of late-stage clinical attrition [16]. Many drugs in the market have been withdrawn due to unexpected drug-induced electrophysiological alterations of the heart [17]. An example is the well-known case of rofecoxib, which was withdrawn from the market due to concerns about increased risk of cardiotoxicity and stroke associated with long-term, high dosage use. The early detection of any drug side effects can halt the process of futile and cost-intensive drug development and, more importantly, safeguard the health of patients. However, physiologically relevant in vitro cardiac models are limited as no current immortalized human cell lines accurately resemble functional cardiomyocytes of the heart for assessing preclinical cardiotoxic responses of drugs. Current cardiac models are typically animal models and in vitro assays, which lack cross-species translation due to differences in biological pathways and pharmacokinetic properties. Studies have already shown that hiPSC-derived cardiomyocytes will react to cardioactive drugs with expected responses, supporting the concept of large scale human cell-based predictive toxicology screens [18]. The use of human pluripotent stem cell (hPSC)-derived cardiomyocytes offers the pharmaceutical industry a precious tool for accelerating clinical introduction, reduce drug development costs and, most importantly, improving drug safety. Currently, GE Healthcare (GE Healthcare PTE Ltd., Singapore, Singapore) is providing cryopreserved hPSC-derived cardiomyocytes (Cytiva $^{\text {Tm }}$ Cardiomyocyte). GE Healthcare has demonstrated that these cardiomyocytes can be used to develop a multiplexed cell imaging-based cardiotoxicity assay with fluorescent probes measuring plasma membrane integrity, cellular calcium levels, cell number and mitochondria status.

A third application of hPSC-derived cardiomyocytes is drug discovery. Over the years, many animal models, particularly mouse, have been generated and widely used. Although these models have shed light on our understanding of the onset and progression of cardiac diseases, they do not always recapitulate the phenotype seen in patients. Several studies have demonstrated the usage of hiPSC-derived cardiomyocytes as models for human cardiac disease [19-21]. Leveraging on models of cardiomyopathies, hPSC-derived cardiomyocytes can thus serve as a platform for screening existing therapies, testing experimental drug combinations and developing new ones. As high-content screens usually require more than $10^{8}$ purified cells [22], challenges to overcome are scalable differentiation methods and purification of cell fractions of interest.

The immense potential of hPSC-derived cardiomyocytes in regenerative medicine, cardiotoxicity pharmacology testing and drug discovery is indeed tantalizing. To effectively serve these applications, however, a reproducible, efficient and cost-effective platform for in vitro cardiomyocyte generation must be developed.

In this review, we examine the progress in development of large scale cardiomyocyte differentiation platforms from hPSCs. We describe the performance of existing reported systems and summarize the main obstacles for further research and optimization.

\section{Expansion of human pluripotent stem cells and cardiogenesis}

The limited proliferating capacity of differentiated cardiomyocytes dictates the design of the production process. It is possible to isolate and cultivate cardiac progenitors as shown in several studies using fluorescence-activated cell sorting of the KDR+/PDGFRA- population [23] or genetically modified NKX2-5 reporter cell line [24]. Even though these progenitors have the potential to be used directly for cell therapy and as the source for cardiomyocyte generation [25], their isolation, maintenance requirements and expansion capacity provide several challenges. Wang and colleagues [26] have comprehensively reviewed the use of cardiac progenitors for cell therapy. Further, the differentiation step of hPSCs to cardiomyocytes has a limited cell expansion of two- to five-fold $[27,28]$. Thus, a scalable, large scale platform for cardiomyocyte production would have to emphasize hPSC expansion rather than cardiomyocyte expansion.

\section{Expansion of human pluripotent cells}

Prior to establishment of a working cell bank and expansion method, it is important to select robust hPSC lines for growth ability and cardiomyocyte differentiation. Especially during the screening of hiPSC clones, it would be ideal to include parameters used in the later expansion as part of the selection criteria. For example, if microcarriers are chosen for hiPSC expansion, then suitable hiPSC clones should also be tested on microcarriers for cell growth and expression of pluripotent markers. In our group, we have observed variability in expansion capability of hPSCs as well as cardiomyocyte differentiation efficiency. Moreover, the mode of cell expansion (for example, feeder cells or extracellular matrix (ECM) coating) can affect cardiomyocyte differentiation efficiency. Hence, it is important to verify these effects before large scale cardiomyocyte generation.

As shown in Figure 1, three hPSC expansion platforms are available. To evaluate these different hPSC expansion platforms for cardiomyocyte generation, we will examine 


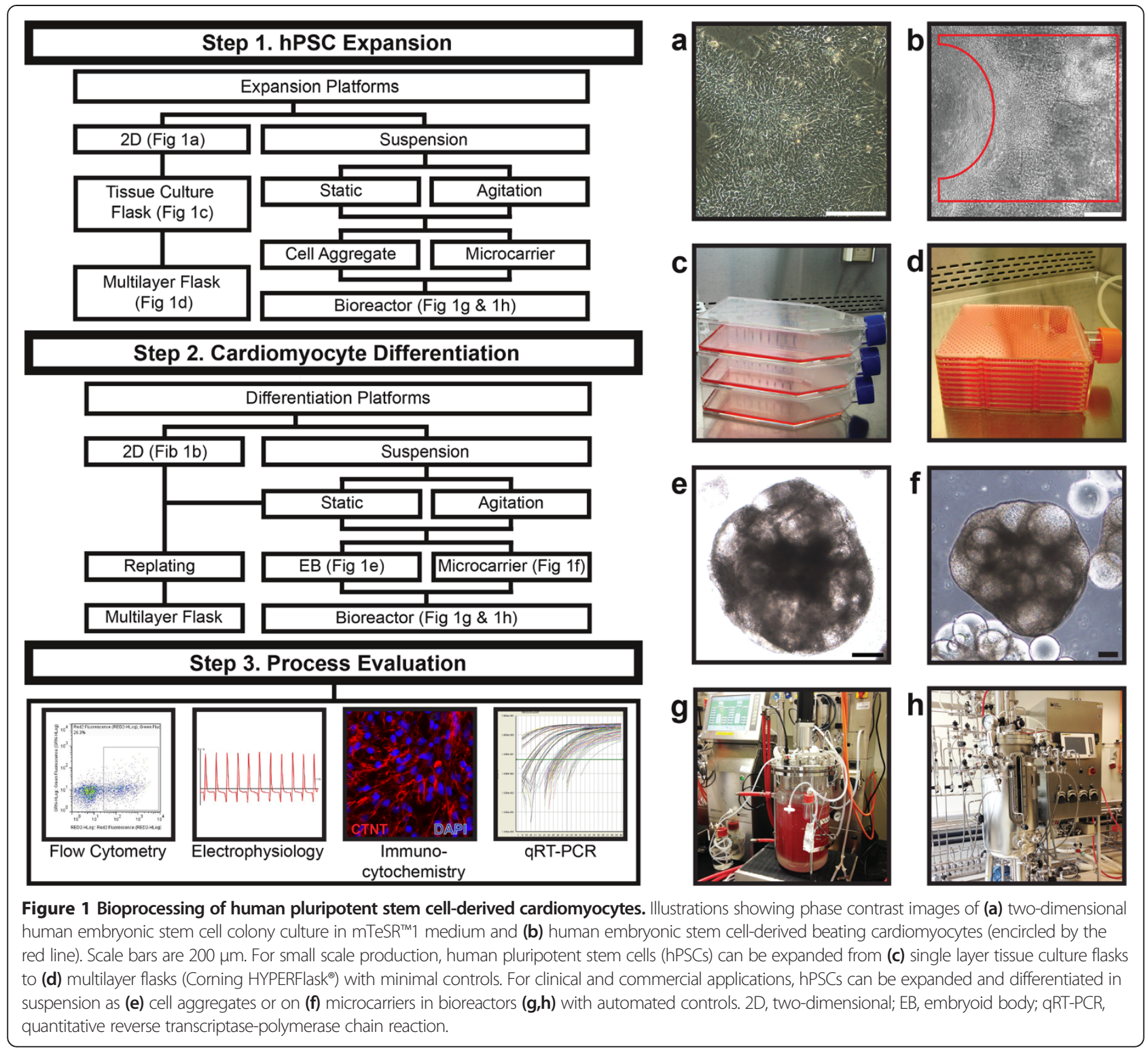

the technical issues involved in each and their implications on subsequent cardiomyocyte differentiation.

\section{Platforms for human pluripotent stem cell expansion}

Two-dimensional tissue culture

Conventional adherent monolayer culture has been widely utilized for hPSC expansion on either feeder cells or ECM (for example, Matrigel, BD Biosciences PTE Ltd., Singapore, Singapore) coated plates in conditioned medium or commercial serum-free medium such as $\mathrm{mTeSR}^{\mathrm{rm}} 1$ (Stemcell Singapore PTE Ltd., Singapore, Singapore) and StemPro ${ }^{\circ} \mathrm{hESC}$ SFM (Life Technologies, Invitrogen Singapore PTE Ltd., Singapore, Singapore) (Figure 1a,c). The majority of reported cardiomyocyte differentiation protocols utilized either hPSCs co-cultured with feeder cells or on Matrigel with feeder cell-conditioned medium (Table 1).
Expansion of hPSCs can be scaled up by using multi-layer flasks (Figure 1d). These multi-layer plates are currently utilized as the cell expansion platform according to good manufacturing practice for supporting cell therapy-related clinical trials [29]. Rowley and colleagues [29] estimated that up to 240 billion hPSCs can be produced with manual handling of 36 multilayer plates. For larger scales, suspension cultures were recommended (for example, microcarrier culture; step 1 in Figure 1g,h) [29]. Another drawback of hPSC expansion in these tissue culture flasks is the lack of representative sampling and online process monitoring or controls. This can undermine the consistency and the quality of the cells. Moreover, the production process requires extensive manual handling and large clean room facilities, which make large scale production expensive. 
Table 1 Methods for cardiomyocyte differentiation from human pluripotent stem cells, ranked by purity of yields

\begin{tabular}{|c|c|c|c|c|c|c|}
\hline $\begin{array}{l}\text { hPSC expansion } \\
\text { platform }\end{array}$ & $\begin{array}{l}\text { Cardiomyocyte differentiation } \\
\text { platform }\end{array}$ & Biomolecules & Purity & Scalability & Comments & Reference \\
\hline \multirow{28}{*}{$\begin{array}{l}\text { Monolayer on feeders } \\
\text { or Matrigel }\end{array}$} & Monolayer & Activin A, BMP4, VEGF, SCF, WNT3a & $24 \%(\mathrm{Nkx} 2.5)$ & + & & [25] \\
\hline & & BMP2, 5\% FBS & $41.6 \%(c \operatorname{crT})$ & + & & [30] \\
\hline & & Activin A, BMP4 & $51 \%(\mathrm{MHC})$ & + & & [10] \\
\hline & & Activin A, BMP4, DKK1 & $54.2 \%(\mathrm{cTnT})$ & + & & [31] \\
\hline & & Activin A, BMP4, FGF2, VEGF, DKK1 & $57.2 \%(c \operatorname{con})$ & + & & [32] \\
\hline & & Activin A, BMP4 & $60 \%$ (a-actinin) & + & & [33] \\
\hline & & Activin A, BMP4, IWP-4 or IWR-1 & $60.6 \%(\mathrm{MHC})$ & + & & [34] \\
\hline & & Activin A, BMP4, FGF2, Noggin, BMS-189453, DKK1 & $73.0 \%(c \operatorname{crT})$ & + & & [35] \\
\hline & & BMP4, ascorbic acid, CHIR99021, IWR-1 & $80 \%(c T n T)$ & + & & [36] \\
\hline & & Activin A, BMP4, FGF2 & $80 \%(c \operatorname{TnT})$ & + & & [27] \\
\hline & & Activin A, BMP4, VEGF & $85.4 \%(c T n T)$ & + & & {$[37]$} \\
\hline & & CHIR99021, IWP-2/IWP-4 & $88.3 \%$ (cTnT) & + & & [38] \\
\hline & & FBS & $90 \%(\mathrm{cTnT})$ & + & & [39] \\
\hline & & CHIR99021, BIO, KY02111, XAV939 & $97.7 \%(c \operatorname{crT})$ & + & & {$[40]$} \\
\hline & Embyoid bodies & Activin A, FGF2 & 23.6\% (beating EBs) & ++ & Forced aggregation & [41] \\
\hline & & Normoxic & 48.3\% (beating EBs) & ++ & Micropatterned; controlled bioreactor & {$[42]$} \\
\hline & & BMP4 & 95.8\% (beating EBs) & + & Replated after 4 days & [43] \\
\hline & & Ascorbic acid & $6.94 \%(c \operatorname{crT})$ & + & Replated after 5 days & [44] \\
\hline & & BMP4, IWP-1 & $15.6 \%(c \operatorname{crT})$ & + & Replated after 4 days & {$[45]$} \\
\hline & & SB203580 & $16 \%(\mathrm{MHC})$ & ++ & & [28] \\
\hline & & SB203580 & $22.0 \%(\mathrm{MHC})$ & ++ & & {$[46]$} \\
\hline & & BMP2, 5-azacytidine & $23.7 \%(c \operatorname{TnT})$ & + & Replated after 6 days & [47] \\
\hline & & SB203580 & $26 \%(\mathrm{MHC})$ & ++ & & [48] \\
\hline & & Activin A, BMP4, FGF2, VEGF, SCF & $26.8 \%(\mathrm{Nkx} 2.5)$ & ++ & Forced aggregation & [24] \\
\hline & & Activin A, BMP4, FGF2, VEGF & $27.1 \%(\mathrm{MHC})$ & + & Replated after 4 days & [49] \\
\hline & & Activin A, BMP4, FGF2, VEGF, DKK1 & $37.2 \%(c \operatorname{con})$ & ++ & & {$[50]$} \\
\hline & & WNT3a & $50 \%$ (a-actinin) & + & Replated after 6 days & [51] \\
\hline & & BMP2 & $53.3 \%(c \operatorname{crT})$ & ++ & & [52] \\
\hline
\end{tabular}


Table 1 Methods for cardiomyocyte differentiation from human pluripotent stem cells, ranked by purity of yields (Continued)

\begin{tabular}{|c|c|c|c|c|c|c|}
\hline & & CHIR99021, IWP-2 & $60 \%(c T n T)$ & ++ & & $\begin{array}{l}\text { Unpublisheo } \\
\text { data }\end{array}$ \\
\hline & & Activin A, BMP4, FGF2, VEGF, DKK1 & $60.2 \%$ (cTnl) & ++ & & [53] \\
\hline & & Activin A, BMP4, FGF2, VEGF, DKK1 & $82 \%(c T n T)$ & ++ & & [23] \\
\hline & & BMP4,FGF2 & $82.3 \%$ (cTnl) & ++ & Forced aggregation & [54] \\
\hline & & Activin A, BMP4, FGF2, VEGF,DKK1 & $91.6 \%(\mathrm{cTnT})$ & ++ & Dissociated EBs & [55] \\
\hline & Microcarriers & SB203580 & $20 \%(\mathrm{MHC})$ & +++ & & [28] \\
\hline \multirow[t]{5}{*}{ Cell aggregate } & Monolayer & Activin A, BMP4, FGF2 & $80 \%(c T n T)$ & + & & {$[27]$} \\
\hline & Embryoid bodies & Activin A, BMP4, FGF2, VEGF, DKK1 & $27 \%(\mathrm{cTnT})$ & +++ & & {$[56]$} \\
\hline & & BMP4 & $36.9 \%(N k x 2.5)$ & + & hESC encapsulation & {$[57]$} \\
\hline & & Activin A, BMP4, FGF2, VEGF, IWR-1 & $80 \%(\mathrm{cTnT})$ & +++ & Controlled bioreactor & {$[27]$} \\
\hline & Microcarriers & No data & & & & \\
\hline Microcarriers & Microcarriers & CHIR99021, IWP-2 & $67 \%(\mathrm{cTnT})$ & +++ & & $\begin{array}{l}\text { Unpublished } \\
\text { data }\end{array}$ \\
\hline
\end{tabular}

BMP, bone morphogenetic protein; $C T n l$, cardiac troponin I; $C T n T$, cardiac troponin T; EB, embryoid body; FBS, fetal bovine serum; FGF, fibroblast growth factor; $h E S C$, human embryonic stem cell; $h P S C$, human pluripotent stem cell; $M H C$, myosin heavy chain; SCF, stem cell factor; VEGF, vascular endothelial growth factor. 


\section{Cell aggregate culture}

Cell aggregate culture has been developed as a scalable expansion platform for hPSCs, which utilizes the characteristic of hPSCs to form aggregates in suspension. hPSCs in single cell suspension usually undergo apoptosis or anoikis. In order to prevent these detrimental effects and establish a viable hPSC suspension culture, hPSCs are partially dissociated in order to form cell aggregates and/or ROCK-Myosin signaling pathway inhibitors (Y27632 or Blebbistatin) are added to improve survival of dissociated hPSCs. Despite significant cell loss during the initial cell aggregate formation (28 to $76 \%$ ), several groups have obtained cell concentrations of 1 to $2 \times 10^{6}$ cells $/ \mathrm{ml}$ with 12.5 - to 17.7 -fold expansion using various hPSC lines [56,58-60]. Since hPSC aggregation is usually associated with spontaneous differentiation, maintaining pluripotency can be demanding. Excessive cell aggregation can induce spontaneous differentiation or necrosis due to nutrient diffusion limitation. The maintenance of aggregate culture is usually carried out by limiting aggregate size to under $500 \mu \mathrm{m}$ by constant disaggregation of the culture. The process is done manually and can affect culture viability and reproducibility. Designing a scalable bioprocess for aggregate culture may require the integration of reproducible, automated processes for repetitive dissociation and formation of uniform cell aggregates. hPSC aggregate cultures were recently reviewed by O'Brien and Laslett [61].

\section{Microcarrier culture}

The development of the microcarrier platform for hPSC expansion has attracted interest for generating cardiomyocytes in a scalable manner. hPSCs cultured on microcarriers exhibited higher cell density and expansion than twodimensional tissue or aggregate cultures, while maintaining pluripotency and karyotypic stability [62]. A recent study by Bardy and colleagues [63] reported the highest cell concentration of $6.1 \times 10^{6}$ cells $/ \mathrm{ml}$ with 20-fold expansion in spinner flasks in serum-free medium. The microcarrierexpanded cells exhibited the capacity to differentiate in situ to neural progenitors [63], endoderm progeny [64], and cardiomyocytes $[62,65]$. However, in order to establish a viable hPSC microcarrier culture, several factors have to be considered, such as microcarrier coating and type, bioreactor design, operating parameters and feeding of medium. These factors can have significant impacts on cell growth, pluripotency and lineage commitments [66]. Compared to other classical microcarrier cultures (for example, Vero cells and mesenchymal stem cells) that form monolayers of cells on microcarriers, hPSCs form multi-layered cell-microcarrier aggregates during propagation. Several groups have screened a variety of microcarriers and coatings for initial cell attachment and hPSC expansion and examined their impact on prolonged cultivation $[64,65,67,68]$. A study by Chen and colleagues [67] examined in detail the effects of shape, size, surface charge, and coatings of microcarriers on hPSC cultivation. Microcarrier shape and size affect the compactness of cell-microcarrier aggregates and consequently cell growth. hPSCs cultured on spherical microcarriers $(\varnothing>180 \mu \mathrm{m})$ exhibited more open structures whereas compact cell-microcarrier aggregates were observed in cylindrical microcarriers [67]. The compactness of cellmicrocarrier aggregates increased with the decrease in microcarrier diameter and this had a negative impact on cell growth, likely due to limited nutrient diffusion for the cells within the aggregates [67]. Matrigel coating has been shown to be critical for hPSC cultivation on microcarriers. Recently, it was shown that laminin and vitronectin can replace Matrigel as defined coatings on microcarriers without compromising cell growth [69]. ROCK inhibitors (Y27632 or Blebbistatin) were later shown to enable hPSC growth on ECM coating-free microcarriers [70].

Scaling up of hPSC microcarrier cultures has been demonstrated by several groups using spinner flasks. Serra and colleagues [71] carried out hPSC microcarrier culturing in bioreactors $(300 \mathrm{ml})$ with automated process control. The authors achieved $2.17 \times 10^{6}$ cells $/ \mathrm{ml}$ in 11 days with a seeding density of $1.5 \times 10^{5}$ cells $/ \mathrm{ml}$ (15-fold expansion). A comprehensive review of the bioprocess parameters for hPSC microcarrier culture was recently published [66]. It is important to note that hPSCs propagated on microcarriers can undergo changes in their phenotype. hPSCs cultured on microcarriers exhibited longer doubling time and a generally lower lactic acid specific production rate than those cultured on a tissue culture plate in serum-free media [72]. Leung and colleagues [73] reported different sensitivities of hPSC lines to shear stress. hPSCs expanded on microcarriers in spinner flasks were able to differentiate efficiently to neural progenitors [63] and endoderm progeny [64]. However, this was not the case for cardiac differentiation. We have observed that hPSCs expanded in agitated microcarrier cultures and differentiated to cardiomyocytes by the p38 MAP kinase protocol $[28,74]$ exhibited lower yields of cardiomyocytes when compared to cells expanded in static microcarrier culture (unpublished results). We hypothesized that the shear effect caused subtle changes in hPSCs that reduced their cardiac differentiation propensity. Hence, it is important to establish quality controls to monitor these subtle changes in hPSC culture before cardiac differentiation.

\section{Cardiogenesis}

Cardiomyocyte differentiation is based on the recapitulation of in vivo cardiogenesis, which depends on a series of complex molecular signaling pathways [75,76]. The differentiation efficiency of these methods depends on the biomolecules used (growth factors or small molecule inhibitors), hPSC culture expansion conditions and the timely activation or deactivation of molecular signals necessary to guide the differentiation toward cardiac lineages (Figure 2) [77]. 


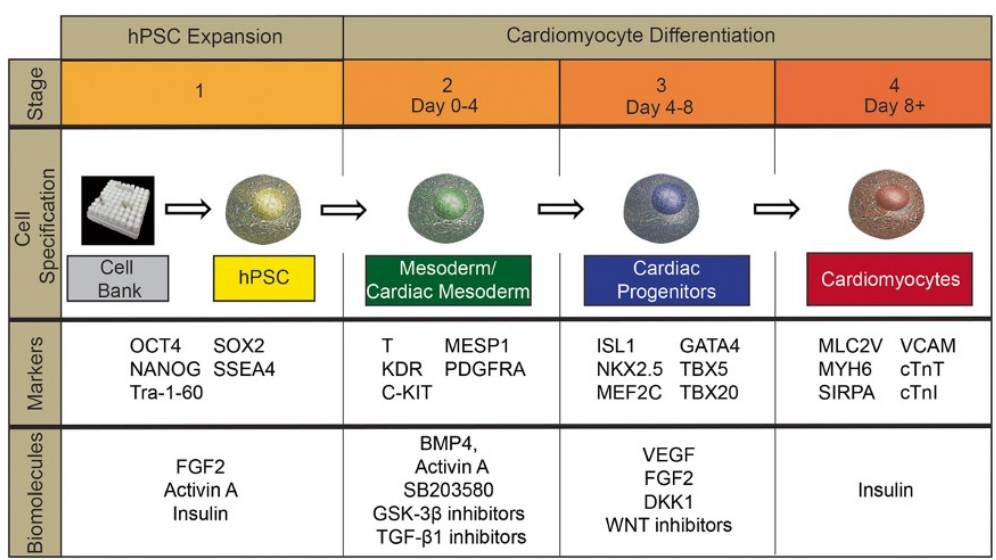

Figure 2 Schematic of human pluripotent stem cell expansion and differentiation to cardiomyocytes. Biomolecules (growth factors and small molecules) play important roles in human pluripotent stem cell (hPSC) expansion and differentiation to cardiomyocytes. Intracellular and cell surface markers associated with each of the three main stages can be used to monitor the progression of differentiation.

Moreover, in all protocols, the concentrations and duration of growth factors or small molecule inhibitor treatments depend on the platform (embryoid body (EB), twodimensional tissue culture or microcarrier cultures) and the hPSC line.

Current cardiac differentiation protocols use either small molecule inhibitors or growth factors to induce the signals for cardiac differentiation. In both cases, the signaling leads to a cascade of three sequential stages: mesodermal induction, cardiac progenitor and cardiomyocyte generation and maintenance [78] (Figure 2). Mesodermal induction, which is monitored by the expression levels of KDR and PDGFR- $\alpha$ $[23,53]$, takes place during the first 3 to 4 days of cardiomyocyte differentiation. This step is usually induced with the growth factors, bone morphogenetic protein (BMP)4 and Activin A, which activate the transforming growth factor (TGF) $-\beta$ signaling pathway, which is crucial for mesoderm differentiation [79]. Mesoderm induction can be also achieved by the addition of small molecules, such as GSK-3 $\beta$ inhibitors (CHIR99021 or BIO) [38,40]. These inhibitors increase endogenous levels of BMP2/4, thus indirectly activating the TGF- $\beta$ signaling pathway [38].

Cardiac progenitor induction is achieved by removal of the TGF- $\beta$ pathway activators and addition of the growth factors, fibroblast growth factor- 2 and/or vascular endothelial growth factor, which activate the ERK signaling pathway [80], or by small molecules that inhibit WNT signaling (for example, KY02111, XAV939, IWP-2 and IWR-1). As these factors drive mesodermal cells towards the cardiac progenitor lineage, they inhibit the development of smooth muscle and endothelial cell lineages [32,50]. A common finding in this stage is that the addition of insulin inhibits the cardiac progenitor differentiation process [49].

The final stage of cardiomyocyte production (day 8 and later) focuses on maturation of cells to cardiomyocytes and their maintenance. Differentiated cardiomyocytes can be maintained in simple serum-free medium, which can minimize outgrowth of fibroblasts and maintain cardiomyocyte purity. Prolonged cultivation of cardiomyocytes has been shown to increase the amount of mature ventricular phenotype [38].

\section{Current platforms for generating cardiomyocytes from human pluripotent stem cells}

After having established a scalable hPSC expansion method, a suitable cardiac differentiation process should be developed. The variety of protocols used by research groups indicates the complexity of the differentiation process and hence the difficulty of applying universally efficient differentiation protocols to the different hPSC lines and culture conditions (Table 1). To date, cardiomyocyte differentiation platforms can be divided into three categories, namely monolayer, EB and microcarrier cultures. Selecting a suitable platform for cardiomyocyte production may depend on several factors, including type of intended application (for example, cell therapy, disease modeling, cardiac toxicology study).

\section{Two-dimensional tissue culture}

In the two-dimensional tissue culture differentiation platform, hPSCs expanded in monolayer can be directly differentiated to cardiomyocytes by a simple change of hPSC growth medium to cardiac differentiation medium. The first efficient directed differentiation protocol was reported by co-culturing hESCs with mouse endoderm-like cells (END-2), which generated 85\% cells exhibiting ventricularlike action potentials [81]. Differentiation protocols were further refined by using more defined conditions with known growth factors, extracellular matrices and eliminating the need for END-2 cells. As shown in Table 1, a simple protocol of using serum-free medium supplemented with Activin A and BMP4 can direct the differentiation to 
cardiomyocytes. In brief, Activin A was added to confluent hPSC monolayer culture for 1 day, then BMP4 for 4 days followed by the removal of growth factors and maintenance in serum-free medium afterward [10]. The protocol was further improved with additional growth factors or small molecules to accommodate interline variability that usually exists among hPSC lines. Recently, small molecules targeting TGF- $\beta$, BMP and WNT signaling have shown the potential to replace growth factors in directing hPSC to cardiomyocytes [38]. In particular, small molecules targeting WNT signaling were the most promising. The sequential activation of WNT via GSK-3 $\beta$ inhibitors (for example, CHIR99021 and BIO) for 1 day, followed by WNT inhibition (for example, KY02111, XAV939, IWP-2 and IWR-1) at day 3 and removal of small molecules after day 5 achieved cardiomyocyte purity of up to $98 \%$ at day 14 [38]. Prolonged cultivation or using the novel WNT inhibitor KY02111 generated more ventricular cardiomyocytes $[38,40]$. These molecules have been applied successfully in cardiomyocyte differentiation using hPSCs cultured on synthetic ECM peptide coated plates [38].

\section{Embryoid body culture}

In the EB differentiation platform, cells from twodimensional cell cultures are usually dissociated into single cells followed by re-aggregation in order to generate homogeneous EB cultures with uniform sizes that are further differentiated to cardiomyocytes (Figure 1e). In general, this dissociation process can lead to significant cell death [82]. Differentiating hPSCs as EBs was first employed in order to accurately recapitulate the complex assembly of cell adhesion and intracellular signaling of early embryogenesis [82]. hPSCs undergo spontaneous differentiation when cultured in suspension as EBs, forming cells of the three lineages. Without guidance towards cardiomyocyte differentiation and control of the culture conditions, the efficiency of cardiomyocyte differentiation was usually low $(<1 \%)$ [30].

Significant progress has been made to improve EB-based cardiomyocyte differentiation efficiency with the identification of growth factors and pathways associated with cardiac differentiation (Table 1). Most of the reported EB cultures use hPSCs expanded in two-dimensional tissue cultures on feeder cells, in particular mouse embryonic fibroblasts. Upon cell dissociation, the residual feeder cells in the cell suspension provide attachment matrices for the generation of EBs. These EBs achieve higher cell viability and aggregate stability compared to EBs generated from two-dimensional tissue cultures without feeder layers (for example, Matrigel) [83].

EB differentiation protocols are more complicated than those used in two-dimensional tissue cultures due to their three-dimensional shape and the effects of the EB microenvironment [82]. Specifically, the size of EBs has been shown to influence cell differentiation towards different lineages [84]. In addition, concentrations of small molecules or growth factors used for differentiation had to be adjusted as these soluble factors have to diffuse through a multilayered cell environment [82]. As cells differentiate toward the cardiac lineage, the formation of excessive aggregate size as a result of cell proliferation or attachment of several aggregates into one (agglomeration) could cause necrosis and consequently reduce cardiomyocyte yield [74]. In order to overcome these problems, several groups have placed single dissociated cells into V- or U-bottom micro-wells coupled with centrifugation to generate uniform cellaggregates with cell numbers ranging from 200 to 1,000 cells per aggregate $[53,58]$. Others have tried encapsulation of hESCs and differentiation to cardiomyocytes [57]. We have tested the use of inert dextran beads as a means to separate cell aggregates from each other. In brief, dextran beads were added to culture wells containing EBs to fill spaces between aggregates, forming two to three layers of beads. Without these inert beads separating the aggregates, frequent manual manipulation of cell aggregates is required in order to prevent agglomeration [74]. In some cases, 4-day-old EBs can be plated on ECM-coated tissue culture plates (for example, gelatine), forming beating cell layers afterward. Under these culture conditions, the yield and purity of the cardiomyocytes improved significantly, achieving 64 to $89 \%$ cardiac troponin $\mathrm{T}$ (cTnT)-positive cardiomyocytes with a variety of hPSC lines [54].

Furthermore, hPSCs can be expanded as cell aggregates in suspension without microcarriers as discussed previously. Two studies showed that these aggregate cultures expanded in a spinner flask can be subsequently differentiated in situ to cardiomyocytes as EBs [56,58]. Matsuura and colleagues [27] reported 80\% cTnT-positive cardiomyocytes generated in a controlled bioreactor. Even though the efficiency of cardiomyocyte differentiation was lower than some of the reported EB-based methods (Table 1), cell aggregate expansion followed by in situ differentiation is more scalable than monolayer expansion.

\section{Microcarrier platform}

Microcarriers can be applied in two ways for cardiomyocyte differentiation. Firstly, they can be used to assist EB formation, stabilization and prevention of agglomeration. Lecina and colleagues [28] used five different microcarriers to examine the effect of microcarrier type, size, shape and concentration on the efficiency of EB-based cardiomyocyte differentiation using SB203580, a mitogen-activated protein kinase inhibitor. Only the small positively charged Tosoh10 beads of $\varnothing 10 \mu \mathrm{m}$, which did not support cell expansion [67], were able to stabilize EB structures and achieve efficient cardiomyocyte differentiation. Using these microcarriers, a cardiomyocyte yield of $90 \%$ beating aggregates and $17 \%$ cells expressing cardiomyocyte markers (myosin heavy chain and alpha-smooth muscle actin) were achieved in 
agitated cultures. In these cultures, two- to three-fold higher efficiency ( 0.28 to 0.62 cardiomyocytes generated per hESC seeded) than the EB-based method ( 0.13 to 0.22 cardiomyocyte generated per hESC seeded) was achieved $[28,74]$. Conventional larger microcarriers (Cytodex1 (Ø190 $\mu \mathrm{m})$ and DE-53 (length $130 \mu \mathrm{m} \times$ diameter $35 \mu \mathrm{m}$ )) that exhibited higher hPSC expansion capability were not efficient in generation of beating cell-microcarrier aggregates during the cardiomyocyte differentiation process.

In a second approach, hPSC microcarrier aggregates generated during cell expansion can be directly differentiated to cardiomyocytes [62,65]. Reported experimental results using this approach are still limited. However, our group has applied microcarrier expanded hPSC cells for cardiomyocyte differentiation and obtained high cell density of $8 \times 10^{6}$ cells $/ \mathrm{ml}$ (40.4-fold cell expansion) with high cardiomyocyte purity of $67 \%$ cTnT and yields of 268 cardiomyocytes per hPSC seeded (Figure 1f; unpublished data). Furthermore, we have observed that the method of hPSC microcarrier culture expansion (static versus agitated condition in spinner flask) can affect the efficiency of cardiomyocyte differentiation. The cause for this phenomenon is still under investigation.

\section{Considerations for scaling up cardiomyocyte production}

We have analyzed three hPSC expansion platforms (twodimensional, cell-aggregate and microcarrier cultures) for their potential to be coupled with various differentiation platforms. These platforms can be applied using a variety of media, culture methods and conditions. In the following section we discuss critical criteria that should be considered in selection of conditions for designing a scalable cardiomyocyte production system.

\section{Selection of cardiomyocyte production platform}

The selection of cardiomyocyte production platform is dictated by the quantity of cardiomyocytes required for a particular application. Three methods of hPSC expansion and seven options for cardiomyocyte differentiation are available for cardiomyocyte production (Table 1). The initial selection of hPSC expansion platform would be based on the amount of cardiomyocytes and the purity needed. The monolayer culture platform can be considered the most straightforward method when compared to suspensionbased systems, achieving relatively high differentiation efficiency (Table 1). For large scale production purposes, cell-aggregate and microcarrier-based systems should be considered. Furthermore, process monitoring and control can be easily applied in suspension platforms to ensure process consistency and reproducibility (Figure 1g,h). We believe the integration of hPSC expansion and cardiomyocyte differentiation as a one unit operation in suspension would be the best approach to scale up cardiomyocyte production.

\section{Bioprocess parameters for cardiomyocyte production in suspension}

hPSC expansion in suspension with automated online process monitoring and controls has been reported [71]. Serra and colleagues [71] examined the effects of oxygen and operation mode (perfusion versus semi-continuous) in hPSC microcarrier cultures [71]. Oxygen was preferable at $30 \%$ air saturation instead of 5\%. hPSCs in perfusion mode (dilution rate of $0.5 \mathrm{day}^{-1}$ ) showed lower lactate production and shorter lag phase than semi-continuous culture $(50 \%$ medium exchange per day) [71]. The perfusion system might be ideal for stage-specific cardiomyocyte differentiation compared to current processes with constant fluctuations in metabolite and growth factor concentrations. Such a system with optimized medium feed can also provide greater efficiencies, replacing current empirical media feeding schemes for hPSC expansion and cardiomyocyte differentiation.

Maintaining a homogeneous suspension culture is critical in process monitoring and controls, but can be challenging considering the size variations of cell aggregate and cellmicrocarrier aggregate cultures. Stirring can also induce shear stress responses. Recently, we have observed that agitation-induced shear stress in spinner microcarrier cultures reduced cardiomyocyte differentiation efficiency. Applying agitation during the first 3 days of cardiomyocyte differentiation (for both microcarrier- and EB-based methods) suppressed cardiomyocyte differentiation. This inhibition could be alleviated when intermittent agitation was employed. The literature reports that shear stress affects the TGF- $\beta$ pathway, which is vital in cardiomyocyte differentiation $[85,86]$.

\section{Medium development}

Medium development is critical in the development of hPSC expansion and differentiation processes. In most papers, hPSCs were expanded in conditioned medium on Matrigelcoated plates or mitotically inactivated feeder cells (Table 1). Medium components like serum replacement (Knockout Serum Replacement (KOSR, Life Technologies)), feeder cells and Matrigel for coating of plates or microcarriers pose risks of pathogen contamination. Therefore, defined xeno-free conditions for hPSC expansion have been developed. Lately, it was reported that hPSCs can be cultured in a simple xeno-free, defined medium with eight components on recombinant vitronectin coated plates [87]. This defined and cheaper medium has significant impact on future hPSC clinical applications where the high medium cost has been one of the bottlenecks for studying large scale process development. This medium can also be adapted for hPSC expansion in aggregate or microcarrier cultures. Significant progress has also been made in establishing defined media for each stage of cardiomyocyte differentiation. Media used by various groups are relatively defined and include known 
growth factors or small molecules with trace amounts of serum albumin (bovine or human) added. Serumsupplemented medium has been used by several groups in generating stable EBs (Table 1). To tackle this issue, $\mathrm{Ng}$ and colleagues [88] developed a defined medium, denoted as APEL, for EB formation and differentiation. To address the cost efficiency, small molecules that target WNT signaling transduction pathways have been found to be suitable replacements for costly growth factors.

\section{Downstream processing}

Studies on development and optimization of downstream processing of hPSC-derived cardiomyocytes are very limited. The process of harvesting cardiomyocytes from monolayer, EB or microcarrier cultures has been demonstrated for small scale research purposes. Monolayer cultures, EBs or cell-microcarrier aggregates are treated with dissociation enzymes followed by passing through a sieve to remove undissociated cell aggregates and microcarriers [74]. These processes are usually not optimized and can become more problematic during scaling up. Enzyme concentration, treatment time, mode of mixing, and sieve loading capacity can affect cell viability and harvest efficiency. Hence, there is a need for further investigation into establishing a scalable and efficient cell harvesting process.

Another aspect of downstream processing is the purification of cardiomyocytes from mixed cell populations $[31,89]$. Considering the amount of cells required for cell therapy, the effects of unwanted cells in cell replacement therapy are largely unknown. Tumorigenicity related to undifferentiated hPSCs remains one of the main concerns, which can be addressed by two approaches. Choo and colleagues [90] used cytotoxic monoclonal antibodies against hPSCs to eliminate undifferentiated hPSCs. Others reported the use of magnetic activated micro-beads coupled to multiple antibodies to remove undifferentiated hPSCs and enrich cardiomyocytes from the heterogeneous cell population after differentiation [31,89,91,92]. However, the antibody-based approach might not be economically viable when scaled up due to the quantity of antibodies needed and their associated costs. Alternatively, Tohyama and colleagues [93] showed a novel approach based on cardiomyocyte metabolic properties, in which cardiomyocytes (up to 99\% purity) were selected from mixed cell populations using glucose-depleted medium containing high lactate. This method is inexpensive, scalable and could be easily integrated into a cardiomyocyte production platform. In addition, hPSC-derived cardiomyocyte cultures contain three sub-phenotypes (atrial, ventricular and nodal). The ratio between these subtypes can be altered by modulating signaling pathways during the differentiation [78]. It was reported that activation of neuregulin/ErbB signaling can increase the nodal fraction within the cardiomyocyte population [94]. Overexpression of microRNA 499, decreased retinoid signaling, electrical stimulation, prolonged cultivation and use of the WNT inhibitor KY02111 were shown to increase the ventricular subtype $[35,38,40,95,96]$. Thus, isolation and purification of the required sub-phenotype could be further investigated in order to improve efficiency. Specifically, enriched nodal cells could potentially form a biological pacemaker whereas ventricular cardiomyocytes could be used for cell therapy after ventricular myocardial infarction.

Lastly, the purified cardiomyocytes can be either cryopreserved or applied directly for tissue engineering. Progress has been made showing the functionality of cryopreserved and dissociated cardiomyocytes. A study by $\mathrm{Xu}$ and colleagues [97] showed that cardiomyocytes can be dissociated into single cells, cryopreserved and thawed without significant loss (70-77\% recovery). These cells could be used for transplantation, comparable to freshly isolated cells [97].

\section{Meeting current good manufacturing practice requirements}

Production of cardiomyocytes at clinical commercial scales that follows the current good manufacturing practice (cGMP) standard will be challenging as most of the current processes are carried out for research purposes without any consideration for cGMP requirements. A defined xeno-free integrated process of expansion, differentiation and downstream purification within a closed system with appropriate monitoring and control systems would be the most suitable for cGMP manufacturing. To characterize the cardiomyocytes produced, quality control assays (step 3 in Figure 1) should be standardized to include cardiomyocyte gene (for example, quantitative RT-PCR) and protein marker (flow cytometry and immunocytochemistry) expression analysis, characterization of electrophysiological properties (multi-electrode array and patch clamp), structural property and organization (electron microscopy) analysis, and determination of calcium signaling (calcium imaging) [98]. Automated high-throughput imaging-based assays developed recently can be advantageous for providing reliable, non-invasive, multi-parameter, real-time monitoring of cardiomyocytes in suspension as EBs or on microcarriers. In cases where downstream purification of cardiomyocytes to subtypes is performed, quality control of cell identity should be done by using the whole cell patch clamping technique, high content immunocytochemistry and flow cytometry [78]. Patch clamping measures the action potential of individual cells and can be both time consuming and low throughput. Flow cytometry analysis using antibodies against these subtypes has been utilized as a high-throughput method. Antibodies against myosin light chain 2 (MLC2) isoforms, namely MLC2a and MLC2v, are widely used to determine ventricular and atrial-like cardiomyocytes. 


\section{Conclusions and future directions}

Cardiac differentiation is an extremely delicate and dynamic process that involves the activation and inhibition of multiple signaling pathways at different time points. Due to this complexity, the development of a protocol that can efficiently differentiate hPSCs to cardiomyocytes in a scalable platform has still yet to be developed and optimized. In this review, current platforms for hPSC expansion have been reviewed for their propensity to be adapted into a scalable bioprocess and their efficiency in terms of cardiomyocyte differentiation. The different protocols developed over the past few years have focused on generation of high purity cardiomyocytes without considering issues involved in scaling up the processes. Establishment of a scalable cardiomyocyte production platform requires a more holistic approach integrating parameters related to scaling up hPSC expansion, cardiomyocyte differentiation and downstream purification into a one unit operation.

In summary, current demands from regenerative medicine, drug testing, and disease modeling require development of cardiomyocyte production processes that have to meet a variety of requirements (for example, serum-free media, cGMP requirements, cost of production, quality control and downstream bioprocessing). Beyond these issues, several others have to be considered in future applications. For example, cardiomyocytes produced according to the current methods are immature in their marker expression and electrical and mechanical functionality [77]. This poses problems for the applications mentioned previously as immature cardiomyocytes may not be the most ideal models of adult cardiomyocytes. Moreover, for cell therapy an appropriate cell delivery method should be developed [77,99]. These challenges call for multidisciplinary efforts that adapt current cardiomyocyte differentiation protocols to develop a cost-effective, scalable and cGMP compliant process, and that resolve issues of downstream purification and quality control as well as cell maturation and delivery systems.

Note: This article is part of a thematic series on Cardiovascular

regeneration edited by Ronald Li. Other articles in the series can be found online at http://stemcellres.com/series/cardiovascular.

\section{Abbreviations}

BMP: Bone morphogenetic protein; CGMP: current good manufacturing practice; CTnT: cardiac troponin T; EB: Embryoid body; ECM: Extracellular matrix; hESC: human embryonic stem cell; hiPSC: human induced pluripotent stem cell; hPSC: human pluripotent stem cell; MLC2: Myosin light chain 2; RT-PCR: Reverse transcriptase-polymerase chain reaction; TGF: Transforming growth factor.

\section{Competing interests}

The authors declare that they have no competing interests.

\section{References}

1. Roger VL, Go AS, Lloyd-Jones DM, Benjamin EJ, Berry JD, Borden WB, Bravata DM, Dai S, Ford ES, Fox CS, Fullerton HJ, Gillespie C, Hailpern SM, Heit JA, Howard VJ, Kissela BM, Kittner SJ, Lackland DT, Lichtman JH, Lisabeth LD, Makuc DM, Marcus GM, Marelli A, Matchar DB, Moy CS, Mozaffarian D, Mussolino ME, Nichol G, Paynter NP, Soliman EZ, et al: Executive summary: heart disease and stroke statistics - 2012 update: a report from the American Heart Association. Circulation 2012, 125:188-197.

2. Nugent HM, Edelman ER: Tissue engineering therapy for cardiovascular disease. Circ Res 2003, 92:1068-1078.

3. Bergmann O, Bhardwaj RD, Bernard S, Zdunek S, Barnabe-Heider F, Walsh S, Zupicich J, Alkass K, Buchholz BA, Druid H, Jovinge S, Frisen J: Evidence for cardiomyocyte renewal in humans. Science 2009, 324:98-102.

4. Anversa P, Kajstura J, Leri A, Bolli R: Life and death of cardiac stem cells: a paradigm shift in cardiac biology. Circulation 2006, 113:1451-1463.

5. Beltrami AP, Barlucchi L, Torella D, Baker M, Limana F, Chimenti S, Kasahara H, Rota M, Musso E, Urbanek K, Leri A, Kajstura J, Nadal-Ginard B, Anversa P: Adult cardiac stem cells are multipotent and support myocardial regeneration. Cell 2003, 114:763-776.

6. Anversa P, Leri A, Kajstura J: Cardiac regeneration. J Am Coll Cardiol 2006, 47:1769-1776.

7. Ameen C, Strehl R, Bjorquist P, Lindahl A, Hyllner J, Sartipy P: Human embryonic stem cells: current technologies and emerging industrial applications. Crit Rev Oncol Hematol 2008, 65:54-80.

8. Itskovitz-Eldor J, Schuldiner M, Karsenti D, Eden A, Yanuka O, Amit M, Soreq $\mathrm{H}$, Benvenisty N: Differentiation of human embryonic stem cells into embryoid bodies compromising the three embryonic germ layers. $\mathrm{Mol}$ Med 2000, 6:88-95.

9. Zwi L, Caspi O, Arbel G, Huber I, Gepstein A, Park IH, Gepstein L: Cardiomyocyte differentiation of human induced pluripotent stem cells. Circulation 2009, 120:1513-1523.

10. Laflamme MA, Chen KY, Naumova AV, Muskheli V, Fugate JA, Dupras SK, Reinecke H, Xu C, Hassanipour M, Police S, O'Sullivan C, Collins L, Chen Y, Minami E, Gill EA, Ueno S, Yuan C, Gold J, Murry CE: Cardiomyocytes derived from human embryonic stem cells in pro-survival factors enhance function of infarcted rat hearts. Nat Biotechnol 2007, 25:1015-1024.

11. Leor J, Gerecht S, Cohen S, Miller L, Holbova R, Ziskind A, Shachar M, Feinberg MS, Guetta E, Itskovitz-Eldor J: Human embryonic stem cell transplantation to repair the infarcted myocardium. Heart 2007, 93:1278-1284.

12. Caspi O, Huber I, Kehat I, Habib M, Arbel G, Gepstein A, Yankelson L, Aronson D, Beyar R, Gepstein L: Transplantation of human embryonic stem cell-derived cardiomyocytes improves myocardial performance in infarcted rat hearts. J Am Coll Cardiol 2007, 50:1884-1893.

13. van Laake LW, Passier R, den Ouden K, Schreurs C, Monshouwer-Kloots J, Ward-van Oostwaard D, van Echteld CJ, Doevendans PA, Mummery CL: Improvement of mouse cardiac function by hESC-derived cardiomyocytes correlates with vascularity but not graft size. Stem Cell Res 2009, 3:106-112.

14. van Laake LW, Passier R, Monshouwer-Kloots J, Verkleij AJ, Lips DJ, Freund C, den Ouden K, Ward-van Oostwaard D, Korving J, Tertoolen LG, van Echteld CJ, Doevendans PA, Mummery CL: Human embryonic stem cell-derived cardiomyocytes survive and mature in the mouse heart and transiently improve function after myocardial infarction. Stem Cell Res 2007, 1:9-24.

15. Laflamme MA, Murry CE: Regenerating the heart. Nat Biotechnol 2005, 23:845-856

16. Kola I, Landis J: Can the pharmaceutical industry reduce attrition rates? Nat Rev Drug Discov 2004, 3:711-715.

17. Braam SR, Tertoolen L, van de Stolpe A, Meyer T, Passier R, Mummery CL: Prediction of drug-induced cardiotoxicity using human embryonic stem cell-derived cardiomyocytes. Stem Cell Res 2010, 4:107-116.

18. Davis RP, van den Berg CW, Casini S, Braam SR, Mummery CL: Pluripotent stem cell models of cardiac disease and their implication for drug discovery and development. Trends Mol Med 2011, 17:475-484.

19. Carvajal-Vergara X, Sevilla A, D'Souza SL, Ang YS, Schaniel C, Lee DF, Yang L, Kaplan AD, Adler ED, Rozov R, Ge Y, Cohen N, Edelmann L, Chang B, Waghray A, Su J, Pardo S, Lichtenbelt KD, Tartaglia M, Gelb BD, Lemischka IR: Patient-specific induced pluripotent stem-cell-derived models of LEOPARD syndrome. Nature 2010, 465:808-812.

20. Moretti A, Bellin M, Welling A, Jung CB, Lam J, Bott-Flugel L, Dorn T, Goedel A Hohnke C, Hofmann F, Seyfarth M, Sinnecker D, Schomig A, Laugwitz KL: Patientspecific induced pluripotent stem-cell models for long-QT syndrome. N Engl J Med 2010, 363:1397-1409. 
21. Novak A, Barad L, Zeevi-Levin N, Shick R, Shtrichman R, Lorber A, ItskovitzEldor J, Binah O: Cardiomyocytes generated from CPVTD307H patients are arrhythmogenic in response to beta-adrenergic stimulation. J Cell Mol Med 2012, 16:468-482.

22. Braam SR, Passier R, Mummery CL: Cardiomyocytes from human pluripotent stem cells in regenerative medicine and drug discovery. Trends Pharmacol $\mathrm{SC}$ 2009, 30:536-545

23. Kattman SJ, Witty AD, Gagliardi M, Dubois NC, Niapour M, Hotta A, Ellis J, Keller G: Stage-specific optimization of activin/nodal and BMP signaling promotes cardiac differentiation of mouse and human pluripotent stem cell lines. Cell Stem Cell 2011, 8:228-240.

24. Elliott DA, Braam SR, Koutsis K, Ng ES, Jenny R, Lagerqvist EL, Biben C, Hatzistavrou T, Hirst CE, Yu QC, Skelton R, Ward-van Oostwaard D, Lim SM, Khammy O, Li X Hawes SM, Davis RP, Goulburn AL, Passier R, Prall OW, Haynes JM, Pouton CW, Kaye DM, Mummery CL, Elefanty AG, Stanley EG: NKX2-5(eGFP/w) hESCs for isolation of human cardiac progenitors and cardiomyocytes. Nat Methods 2011, 8:1037-1040.

25. Wong SS, Bernstein HS: Cardiac regeneration using human embryonic stem cells: producing cells for future therapy. Regen Med 2010, 5:763-775.

26. Wang WE, Chen $X$, Houser SR, Zeng C: Potential of cardiac stem/progenitor cells and induced pluripotent stem cells for cardiac repair in ischaemic heart disease. Clin Sci 2013, 125:319-327.

27. Matsuura K, Wada M, Shimizu T, Haraguchi Y, Sato F, Sugiyama K, Konishi K, Shiba Y, Ichikawa H, Tachibana A, Ikeda U, Yamato M, Hagiwara N, Okano T: Creation of human cardiac cell sheets using pluripotent stem cells. Biochem Biophys Res Commun 2012, 425:321-327.

28. Lecina M, Ting S, Choo A, Reuveny S, Oh S: Scalable platform for hESC differentiation to cardiomyocytes in suspended microcarrier cultures. Tissue Eng Part C Methods 2010, 16:1609-1619.

29. Rowley J, Abraham E, Campbell A, Brandwein H, Oh S: Meeting lot-size challenges of manufacturing adherent cells for therapy. BioProcess Int 2012, 10:16-22.

30. Laflamme MA, Chen KY, Naumova AV, Muskheli V, Fugate JA, Dupras SK, Reinecke H, Xu C, Hassanipour M, Police S, O'Sullivan C, Collins L, Chen Y, Minami E, Gill EA, Ueno S, Yuan C, Gold J, Murry CE: Cardiomyocytes derived from human embryonic stem cells in pro-survival factors enhance function of infarcted rat hearts. Nat Biotechnol 2007, 25:1015-1024.

31. Uosaki H, Fukushima H, Takeuchi A, Matsuoka S, Nakatsuji N, Yamanaka S, Yamashita JK: Efficient and scalable purification of cardiomyocytes from human embryonic and induced pluripotent stem cells by VCAM1 surface expression. PLOS ONE 2011, 6:e23657

32. Woll PS, Morris JK, Painschab MS, Marcus RK, Kohn AD, Biechele TL, Moon RT, Kaufman DS: Wnt signaling promotes hematoendothelial cell development from human embryonic stem cells. Blood 2008, 111:122-131.

33. Melkoumian Z, Weber JL, Weber DM, Fadeev AG, Zhou Y, Dolley-Sonneville $P$, Yang J, Qiu L, Priest CA, Shogbon C, Martin AW, Nelson J, West P, Beltzer JP, Pal S, Brandenberger $R$ : Synthetic peptide-acrylate surfaces for long-term selfrenewal and cardiomyocyte differentiation of human embryonic stem cells. Nat Biotechnol 2010, 28:606-610.

34. Hudson J, Titmarsh D, Hidalgo A, Wolvetang E, Cooper-White J: Primitive cardiac cells from human embryonic stem cells. Stem Cells Dev 2012, 21:1513-1523.

35. Zhang Q, Jiang J, Han P, Yuan Q, Zhang J, Zhang X, Xu Y, Cao H, Meng Q, Chen L, Tian T, Wang X, Li P, Hescheler J, Ji G, Ma Y: Direct differentiation of atrial and ventricular myocytes from human embryonic stem cells by alternating retinoid signals. Cell Res 2011, 21:579-587.

36. Cao N, Liang H, Huang J, Wang J, Chen Y, Chen Z, Yang HT: Highly efficient induction and long-term maintenance of multipotent cardiovascular progenitors from human pluripotent stem cells under defined conditions. Cell Res 2013, 23:1119-1132.

37. Ye L, Zhang S, Greder L, Dutton J, Keirstead SA, Lepley M, Zhang L, Kaufman $D$, Zhang J: Effective cardiac myocyte differentiation of human induced pluripotent stem cells requires VEGF. PLOS ONE 2013, 8:e53764.

38. Lian X, Hsiao C, Wilson G, Zhu K, Hazeltine LB, Azarin SM, Raval KK, Zhang J, Kamp TJ, Palecek SP: Robust cardiomyocyte differentiation from human pluripotent stem cells via temporal modulation of canonical Wnt signaling. Proc Natl Acad Sci U S A 2012, 109:E1848-E1857.

39. Moon SH, Ban K, Kim C, Kim SS, Byun J, Song MK, Park IH, Yu SP, Yoon YS: Development of a novel two-dimensional directed differentiation system for generation of cardiomyocytes from human pluripotent stem cells. Int J Cardiol 2013, 168:41-52.

40. Minami I, Yamada K, Otsuji TG, Yamamoto T, Shen Y, Otsuka S, Kadota S, Morone N, Barve M, Asai Y, Tenkova-Heuser T, Heuser JE, Uesugi M, Aiba K, Nakatsuji N: A small molecule that promotes cardiac differentiation of human pluripotent stem cells under defined, cytokine- and xeno-free conditions. Cell reports 2012, 2:1448-1460.

41. Burridge PW, Anderson D, Priddle H, Barbadillo Munoz MD, Chamberlain S, Allegrucci C, Young LE, Denning C: Improved human embryonic stem cell embryoid body homogeneity and cardiomyocyte differentiation from a novel V-96 plate aggregation system highlights interline variability. Stem Cells 2007, 25:929-938.

42. Niebruegge S, Nehring A, Bar H, Schroeder M, Zweigerdt R, Lehmann J: Cardiomyocyte production in mass suspension culture: embryonic stem cells as a source for great amounts of functional cardiomyocytes. Tissue Eng Part A 2008, 14:1591-1601

43. Takei S, Ichikawa H, Johkura K, Mogi A, No H, Yoshie S, Tomotsune D, Sasaki K. Bone morphogenetic protein-4 promotes induction of cardiomyocytes from human embryonic stem cells in serum-based embryoid body development. Am J Physiol Heart Circ Physiol 2009, 296:H1793-H1803.

44. Cao N, Liu Z, Chen Z, Wang J, Chen T, Zhao X, Ma Y, Qin L, Kang J, Wei B, Wang L, Jin $Y$, Yang HT: Ascorbic acid enhances the cardiac differentiation of induced pluripotent stem cells through promoting the proliferation of cardiac progenitor cells. Cell Res 2012, 22:219-236.

45. Ren Y, Lee MY, Schliffke S, Paavola J, Amos PJ, Ge X, Ye M, Zhu S, Senyei G, Lum $L$, Ehrlich BE, Qyang Y: Small molecule Wnt inhibitors enhance the efficiency of BMP-4-directed cardiac differentiation of human pluripotent stem cells. J Mol Cell Cardiol 2011, 51:280-287.

46. Graichen R, Xu X, Braam SR, Balakrishnan T, Norfiza S, Sieh S, Soo SY, Tham SC, Mummery C, Colman A, Zweigerdt R, Davidson BP: Enhanced cardiomyogenesis of human embryonic stem cells by a small molecular inhibitor of p38 MAPK. Differentiation 2008, 76:357-370.

47. Gai H, Leung EL, Costantino PD, Aguila JR, Nguyen DM, Fink LM, Ward DC Ma Y: Generation and characterization of functional cardiomyocytes using induced pluripotent stem cells derived from human fibroblasts. Cell Biol Int 2009, 33:1184-1193.

48. Gaur M, Ritner C, Sievers R, Pedersen A, Prasad M, Bernstein HS, Yeghiazarians Y: Timed inhibition of p38MAPK directs accelerated differentiation of human embryonic stem cells into cardiomyocytes. Cytotherapy 2010, 12:807-817.

49. Willems E, Spiering S, Davidovics H, Lanier M, Xia Z, Dawson M, Cashman J, Mercola M: Small-molecule inhibitors of the Wnt pathway potently promote cardiomyocytes from human embryonic stem cell-derived mesoderm. Circ Res 2011, 109:360-364.

50. Yang L, Soonpaa MH, Adler ED, Roepke TK, Kattman SJ, Kennedy M, Henckaerts E, Bonham K, Abbott GW, Linden RM, Field LJ, Keller GM: Human cardiovascular progenitor cells develop from a KDR+embryonicstem-cell-derived population. Nature 2008, 453:524-528.

51. Tran TH, Wang X, Browne C, Zhang Y, Schinke M, Izumo S, Burcin M: Wnt3a-induced mesoderm formation and cardiomyogenesis in human embryonic stem cells. Stem Cells 2009, 27:1869-1878.

52. Pal R, Mamidi MK, Das AK, Bhonde R: Comparative analysis of cardiomyocyte differentiation from human embryonic stem cells under 3-D and 2-D culture conditions. J Biosci Bioeng 2013, 115:200-206.

53. Sa S, McCloskey KE: Stage-specific cardiomyocyte differentiation method for H7 and H9 human embryonic stem cells. Stem Cell Rev 2012, 8:1120-1128.

54. Burridge PW, Thompson S, Millrod MA, Weinberg S, Yuan X, Peters A Mahairaki V, Koliatsos VE, Tung L, Zambidis ET: A universal system for highly efficient cardiac differentiation of human induced pluripotent stem cells that eliminates interline variability. PLOS ONE 2011, 6:e18293.

55. Shinozawa T, Furukawa H, Sato E, Takami K: A novel purification method of murine embryonic stem cell- and human-induced pluripotent stem cellderived cardiomyocytes by simple manual dissociation. J Biomol Screen 2012, 17:683-691.

56. Chen VC, Couture SM, Ye J, Lin Z, Hua G, Huang HI, Wu J, Hsu D, Carpenter MK, Couture LA: Scalable GMP compliant suspension culture system for human ES cells. Stem Cell Res 2012, 8:388-402.

57. Jing D, Parikh A, Tzanakakis ES: Cardiac cell generation from encapsulated embryonic stem cells in static and scalable culture systems. Cell Transplant 2010, 19:1397-1412

58. Singh H, Mok P, Balakrishnan T, Rahmat SNB, Zweigerdt R: Up-scaling single cell-inoculated suspension culture of human embryonic stem cells. Stem Cell Res 2010, 4:165-179.

59. Olmer R, Haase A, Merkert S, Cui W, Paleček J, Ran C, Kirschning A, Scheper T, Glage S, Miller K, Curnow EC, Hayes ES, Martin U: Long term expansion of undifferentiated human iPS and ES cells in suspension culture using a defined medium. Stem Cell Res 2010, 5:51-64. 
60. Amit M, Laevsky I, Miropolsky Y, Shariki K, Peri M, Itskovitz-Eldor J: Dynamic suspension culture for scalable expansion of undifferentiated human pluripotent stem cells. Nat Protocols 2011, 6:572-579.

61. O'Brien C, Laslett AL: Suspended in culture - human pluripotent cells for scalable technologies. Stem Cell Res 2012, 9:167-170.

62. Oh SKW, Chen AK, Mok Y, Chen X, Lim U-M, Chin A, Choo ABH, Reuveny S: Long-term microcarrier suspension cultures of human embryonic stem cells. Stem Cell Res 2009, 2:219-230.

63. Bardy J, Chen A, Lim YM, Wu S, Wei S, Weiping H, Chan K, Reuveny S, Oh SKW: Microcarrier suspension cultures produce high yields of neural progenitor cells from human pluripotent stem cells. Tissue Eng Part C Methods 2013, 19:166-180.

64. Lock LT, Tzanakakis ES: Expansion and differentiation of human embryonic stem cells to endoderm progeny in a microcarrier stirred-suspension culture Tissue Eng Part A 2009, 15:2051-2063.

65. Phillips BW, Horne R, Lay TS, Rust WL, Teck TT, Crook JM: Attachment and growth of human embryonic stem cells on microcarriers. J Biotechnol 2008 138:24-32

66. Chen A, Reuveny S, Oh SK: Application of human mesenchymal and pluripotent stem cell microcarrier cultures in cellular therapy: achievements and future direction. Biotechnol Adv 2013, 31:1032-1046.

67. Chen AK-L, Chen X, Choo ABH, Reuveny S, Oh SKW: Critical microcarrier properties affecting the expansion of undifferentiated human embryonic stem cells. Stem Cell Res 2011, 7:97-111.

68. Nie Y, Bergendahl V, Hei DJ, Jones JM, Palecek SP: Scalable culture and cryopreservation of human embryonic stem cells on microcarriers. Biotechnol Prog 2009, 25:20-31.

69. Heng BC, Li J, Chen AK-L, Reuveny S, Cool SM, Birch WR, Oh SK-W: Translating human embryonic stem cells from 2-dimensional to 3-dimensional cultures in a defined medium on laminin- and vitronectin-coated surfaces. Stem Cells Dev 2012, 21:1701-1715.

70. Medicinal and other products and human and animal transmissible spongiform encephalopathies: memorandum from a WHO meeting. Bull World Health Organ 1997, 75:505-513.

71. Serra M, Brito C, Sousa MFQ, Jensen J, Tostões R, Clemente J, Strehl R, Hyllner J, Carrondo MJT, Alves PM: Improving expansion of pluripotent human embryonic stem cells in perfused bioreactors through oxygen control. J Biotechnol 2010, 148:208-215.

72. Chen $\mathrm{X}$, Chen A, Woo TL, Choo ABH, Reuveny S, Oh SKW: Investigations into the metabolism of two-dimensional colony and suspended microcarrier cultures of human embryonic stem cells in serum-free media. Stem Cells Dev 2010, 19:1781-1792.

73. Leung HW, Chen A, Choo A, Reuveny S, Oh S: Agitation can induce differentiation of human pluripotent stem cells in microcarrier cultures. Tissue Eng Part C Methods 2010, 17:165-172.

74. Ting S, Lecina M, Reuveny S, Oh S: Differentiation of human embryonic stem cells to cardiomyocytes on microcarrier cultures. Curr Protocols Stem Cell Biol 2012. Chapter 1:Unit1D 7.

75. Wagner M, Siddiqui MA: Signal transduction in early heart development (I): cardiogenic induction and heart tube formation. Exp Biol Med (Maywood) 2007, 232:852-865

76. Wagner M, Siddiqui MA: Signal transduction in early heart development (II): ventricular chamber specification, trabeculation, and heart valve formation. Exp Biol Med (Maywood) 2007, 232:866-880.

77. Burridge PW, Keller G, Gold JD, Wu JC: Production of de novo cardiomyocytes: human pluripotent stem cell differentiation and direct reprogramming. Cell Stem Cell 2012, 10:16-28

78. Xu C: Differentiation and enrichment of cardiomyocytes from human pluripotent stem cells. J Mol Cell Cardiol 2012, 52:1203-1212.

79. Watabe T, Miyazono K: Roles of TGF-beta family signaling in stem cell renewal and differentiation. Cell Res 2009, 19:103-115.

80. Chen Y, Amende I, Hampton TG, Yang Y, Ke Q, Min JY, Xiao YF, Morgan JP: Vascular endothelial growth factor promotes cardiomyocyte differentiation of embryonic stem cells. Am J Physiol Heart Circ Physiol 2006, 291:H1653-H1658.

81. Mummery C, Ward-van Oostwaard D, Doevendans P, Spijker R, van den Brink S, Hassink R, van der Heyden M, Opthof T, Pera M, de la Riviere AB, Passier R, Tertoolen L: Differentiation of human embryonic stem cells to cardiomyocytes: role of coculture with visceral endoderm-like cells. Circulation 2003, 107:2733-2740.

82. Bratt-Leal AM, Carpenedo RL, McDevitt TC: Engineering the embryoid body microenvironment to direct embryonic stem cell differentiation. Biotechnol Prog 2009, 25:43-51.
83. Denning $C$, Allegrucci $C$, Priddle $H$, Barbadillo-Munoz MD, Anderson D, Self $T$, Smith NM, Parkin CT, Young LE: Common culture conditions for maintenance and cardiomyocyte differentiation of the human embryonic stem cell lines, BG01 and HUES-7. Int J Dev Biol 2006, 50:27-37.

84. Peerani R, Rao BM, Bauwens C, Yin T, Wood GA, Nagy A, Kumacheva E, Zandstra PW: Niche-mediated control of human embryonic stem cell self-renewal and differentiation. EMBO J 2007, 26:4744-4755.

85. Wang W, Ha CH, Jhun BS, Wong C, Jain MK, Jin ZG: Fluid shear stress stimulates phosphorylation-dependent nuclear export of HDAC5 and mediates expression of KLF2 and eNOS. Blood 2010, 115:2971-2979.

86. Dimmeler S, Assmus B, Hermann C, Haendeler J, Zeiher AM: Fluid shear stress stimulates phosphorylation of Akt in human endothelial cells: involvement in suppression of apoptosis. Circ Res 1998, 83:334-341.

87. Chen G, Gulbranson DR, Hou Z, Bolin JM, Ruotti V, Probasco MD, Smuga-Otto K, Howden SE, Diol NR, Propson NE, Wagner R, Lee GO, Antosiewicz-Bourget J, Teng JM, Thomson JA: Chemically defined conditions for human iPSC derivation and culture. Nat Methods 2011, 8:424-429.

88. Ng ES, Davis R, Stanley EG, Elefanty AG: A protocol describing the use of a recombinant protein-based, animal product-free medium (APEL) for human embryonic stem cell differentiation as spin embryoid bodies. Nat Protoc 2008 3:768-776.

89. Van Hoof D, Dormeyer W, Braam SR, Passier R, Monshouwer-Kloots J, Ward-van Oostwaard D, Heck AJ, Krijgsveld J, Mummery CL: Identification of cell surface proteins for antibody-based selection of human embryonic stem cell-derived cardiomyocytes. J Proteome Res 2010, 9:1610-1618.

90. Choo AB, Tan HL, Ang SN, Fong WJ, Chin A, Lo J, Zheng L, Hentze H, Philp RJ, Oh SKW, Yap M: Selection against undifferentiated human embryonic stem cells by a cytotoxic antibody recognizing podocalyxin-like protein-1. Stem Cells 2008, 26:1454-1463.

91. Dubois NC, Craft AM, Sharma P, Elliott DA, Stanley EG, Elefanty AG, Gramolini A, Keller G: SIRPA is a specific cell-surface marker for isolating cardiomyocytes derived from human pluripotent stem cells. Nat Biotechnol 2011, 29:1011-1018.

92. Schriebl K, Satianegara G, Hwang A, Tan HL, Fong WJ, Yang HH, Jungbauer A, Choo A: Selective removal of undifferentiated human embryonic stem cells using magnetic activated cell sorting followed by a cytotoxic antibody. Tissue Eng Part A 2012, 18:899-909.

93. Tohyama S, Hattori F, Sano M, Hishiki T, Nagahata Y, Matsuura T, Hashimoto $H$, Suzuki T, Yamashita H, Satoh Y, Egashira T, Seki T, Muraoka N, Yamakawa H, Ohgino Y, Tanaka T, Yoichi M, Yuasa S, Murata M, Suematsu M, Fukuda K: Distinct metabolic flow enables large-scale purification of mouse and human pluripotent stem cell-derived cardiomyocytes. Cell Stem Cell 2013, 12:127-137.

94. Zhu WZ, Xie Y, Moyes KW, Gold JD, Askari B, Laflamme MA: Neuregulin/ErbB signaling regulates cardiac subtype specification in differentiating human embryonic stem cells. Circ Res 2010, 107:776-786.

95. Chan YC, Ting S, Lee YK, Ng KM, Zhang J, Chen Z, Siu CW, Oh SK, Tse HF: Electrical stimulation promotes maturation of cardiomyocytes derived from human embryonic stem cells. J Cardiovasc Trans/ Res 2013, 6:989-999.

96. Fu JD, Rushing SN, Lieu DK, Chan CW, Kong CW, Geng L, Wilson KD, Chiamvimonvat N, Boheler KR, Wu JC, Keller G, Hajjar RJ, Li RA: Distinct roles of microRNA-1 and -499 in ventricular specification and functional maturation of human embryonic stem cell-derived cardiomyocytes. PLOS ONE 2011, 6:e27417.

97. Xu C, Police S, Hassanipour M, Li Y, Chen Y, Priest C, O'Sullivan C, Laflamme MA, Zhu WZ, Van Biber B, Hegerova L, Yang J, Delavan-Boorsma K, Davies A, Lebkowski J, Gold JD: Efficient generation and cryopreservation of cardiomyocytes derived from human embryonic stem cells. Regen Med 2011, 6:53-66.

98. Mordwinkin NM, Burridge PW, Wu JC: A review of human pluripotent stem cell-derived cardiomyocytes for high-throughput drug discovery, cardiotoxicity screening, and publication standards. J Cardiovasc Trans/ Res 2013, 6:22-30.

99. Buikema J, van der Meer P, Sluijter JP, Domian IJ: Engineering myocardial tissue: the convergence of stem cells biology and tissue engineering technology. Stem Cells 2013. in press.

\section{doi:10.1186/scrt401}

Cite this article as: Chen et al:: Considerations in designing systems for large scale production of human cardiomyocytes from pluripotent stem cells. Stem Cell Research \& Therapy 2014 5:12. 